\title{
The Faculty Ulysses Contract
}

\section{Prof. Joe Tranquillo, Bucknell University}

Joe Tranquillo is an Associate Professor of Biomedical and Electrical Engineering at Bucknell University. Joe was the founder and inaugural chair of the Biomedical Engineering Society Undergraduate Research Track, and co-founder of the KEEN Winter Interdisciplinary Design Experience. He currently serves as the Chair of the American Society for Engineering Education (ASEE) Biomedical Engineering Division (BED), the co-director of the Institute for Leadership in Technology and Management (ILTM) and is co-editor of the Morgan and Claypool biomedical engineering book series. Joe is the author of three undergraduate textbooks. His work has been featured on the Discovery Channel, TEDx, US News and World Report, and CNN Health. He has won the national ASEE BED Teaching Award, Bucknell's Presidential Teaching Award, and is currently a National Academy of Engineering Frontiers of Engineering Education Fellow and an NSF Pathways to Innovation Faculty Fellow. When not working Joe enjoys improvisational dance and music, running trail marathons, backpacking, brewing Belgian beers and most of all enjoying time with his children and wife. 


\title{
The Faculty Ulysses Contract
}

\author{
Joe Tranquillo \\ jvt002@bucknell.edu \\ Biomedical Engineering \\ Bucknell University
}

\begin{abstract}
Come this way, honored Odysseus, great glory of the Achaians, and stay your ship, so that you can listen here to our singing; for no one else has ever sailed past this place in his black ship until he has listened to the honey-sweet voice that issues from our lips; then goes on, well-pleased, knowing more than ever he did; for we know everything that the Argives and Trojans did and suffered in wide Troy through the gods' despite. Over all the generous earth we know everything that happens. ${ }^{1}$
\end{abstract}

\section{Introduction}

Every teacher has encountered the inherent conflict that is embedded in a question from a student. On the one hand, the simplest thing to do is to answer the question. But, answering the question can too easily reinforce the sage-on-the-stage model, where the instructor is the keeper of knowledge ${ }^{2,3}$. What the student gains is the answer, but it is unclear if the student can transfer the knowledge they have gained to a new situation. The student does learn one thing, however, and that is that the instructor can be a excellent shortcut to doing well in the class without needing to truly learn the material. The conclusion of such an approach is that a course becomes a rite of passage and grades a means of credentialing ${ }^{4}$.

An alternative is to withhold the answer and challenge the student to discover the answer on their own. This is the basis of pedagogical techniques such as Inductive Learning, Problem Based Learning, Flipped Classrooms and Just-In-Time Teaching ${ }^{2,5,6,7}$. The faculty know the material but intentionally design activities that allow students to discover the material for themselves. We become the "guide on the side". This seems better if learning is defined as the ability to transfer knowledge and skills to new domains. But the inductive approach also enables the instructor to hide (from the perspective of the students) behind fancy sounding pedagogical techniques. In reality, we are still a sage, we simply don't stand on the stage all the time. An inductive classroom is therefore only "flipped" in delivery, as we are still very much the arbiters of skill and knowledge.

What I will present is a way to assign problems and projects where the instructor is not the content expert. Faculty instead make a contract with their students to guide them without being able to direct them with regard to content. The end goal is for students to experience what it is like to 
drive forward their own learning. I will call such an approach a Faculty Ulysses Contract. It is not an alternative to other pedagogical approaches, but rather can be used in synergy with many other forms of pedagogy.

First we will explore the historical context of the Ulysses Contract and how it has been used in other fields. Next we will explore what faculty and students gain from issuing Faculty Ulysses Contracts as well as how to weave in other pedagogical techniques. The article will conclude with some general advice on how to implement Faculty Ulysses Contracts. Throughout the paper are case studies that span required and elective courses, disciplinary and interdisciplinary environments, for-credit and extra/co-curricular programs. Also scattered throughout are answers to the common practical and philisophical barriers to faculty adoption. The paper concludes with a teaching war story along with how I recovered.

\section{Ulysses and The Sirens}

Ulysses is the hero of the epic poem the Odyssey. The contract comes from a very particular scene where Ulysses and his crew are sailing toward the sirenum scopuli islands. On the island are Sirens who have the most beautiful voices, but all who hear them cannot help but steer their ship into the rocky cliffs of the islands. Ulysses, wanting to the be first to hear the sirens and live to tell the story, instructs his crew to tie him to the mast, plug their ears and not listen to any of his pleading until they are clear of the islands. The crew follow his orders and Ulysses becomes the first person to hear the sirens and live.

The scene has come to illustrate how self-imposed decisions at one time can constrain future actions. We know from a long line of psychological studies that when we make decisions in the moment, they are not always well thought out and may in fact be detrimental to us in the future $^{8,9}$. And even when we make a decision beforehand, if it is too easy to break that decision when it matters, it is an empty decision. Constraining our future actions in such a way that we cannot change that decision has becoming known as a Ulysses Contract (sometimes also called Self-Paternalism ${ }^{10}$ ). The canonical example comes from the therapy of addiction, where an alcoholic will pour their liquor down the drain in a moment of clarity to prevent drinking at a later moment of weakness. As individuals we do the same, making professional and personal sacrifices, saving our earnings for retirement, and investing time and energy into our children when they are young. Cultures also engage in a similar type of collective Ulysses Contract when they pass laws that might be painful in the short-term but beneficial in the long run. The theoretical grounding for the contract comes from game theory where choosing to move down a one-way path forever changes future strategies and actions ${ }^{11,12}$.

Although the Sirens are often portrayed as sexy temptresses in pop culture, what they are offering, as evidenced in the quote above, is knowledge. The dilemma is that much of our educational system enables, and in most cases rewards, taking the shortest path to knowledge. As a result, even very well-tested pedagogy (e.g. problem based learning, active learning ${ }^{5}$ ) can break down when a faculty member is continuously being pestered to yield information. What compounds this dilemma is that sometimes answering a question might be essential while at other times it is merely 
a convenience for the students. There is no clean dividing line between the two. The result is that a vicious cycle of cue-action-reward ${ }^{13,14}$ is established in the classroom. The student asks a question (cue), the faculty member resists answering (action), and the student complains (no reward for faculty or student). The idealistic claim of inductive learning is that through repeated use, a student will learn that a faculty member should not be their first-stop, and begins to look for the answer themselves. Their action is then rewarded with the recognition of a deeper understanding and a virtuous cycle is reinforced.

What can too easily destroy this cycle is that it is potentially weak at every point. The student may simply stop asking questions (no cue), and the faculty member may not know if this is because students are working hard or not working at all. The faculty member may in a moment of weakness cave in and start answering questions (a sage-type action). The reward may become intentionally or unintentionally focused on a pure right-wrong dichotomy, reinforcing grades as the focus rather than transferable learning and good learning habits. The literature on inductive pedagogy has answers to all of these potential means of short circuiting the learning environment that are summed up in best practices ${ }^{2,15,16}$. But unless all of these best practices are followed, the learning environment can break down.

What is needed is a way to change the cues and rewards to establish a robust virtuous cycle of good learning habits. What we propose here is that moving the source of knowledge out of the hands of the faculty member is one way to make the learning process more robust. To more clearly illustrate how this is implemented in a classroom, a case study is presented from a required juniorlevel biomedical engineering signals and systems course.

\section{Case Study: Biomusical Instruments, Interactive Fashion and Toys (BMEG 350)}

A traditional signals and system course will focus on a range of theoretical topics and perhaps supplement by labs or long-term projects ${ }^{17}$. In this traditional format, learning is a flow of knowledge from the faculty member to the students. Even in more inquiry-based courses, the instructor has in mind the core knowledge, and structures assignments in such a way that students discover on their own what the instructor intends for them to discover.

To flip this paradigm, I brought into my class the Bucknell Improvisation Intensive Ensemble (BIIE). BIIE is a collective of musicians, dancers, poets, and artists, led by a jazz musician turned clinical professor of music, who co-improvise. I challenged the BIIE musicians and my engineering students to co-create non-traditional "biomusical instruments". Engineering teams worked with the musicians to design and build a device that would record one or more biological signals and transform them into coherent sound. A requirement was that the system should work in realtime and contain no prerecorded sound sequences. Both constraints were made to allow musicians to freely improvise. BIIE visited the class on several occasions and made suggestions throughout the semester. They pushed the engineering students in new directions, often teaching them a good deal of music theory in the process ${ }^{18}$.

The challenge to the musicians was that they would performed in public on these instruments 
at the end of the semester. In this regard, the faculty leader of BIIE was also engaged in a Faculty Ulysses Contract with his own students - challenging them to do something that he had never done before. A significant byproduct of the collaboration was that the musicians learned a good deal of signals and systems.

While the biomusic project clearly was a Faculty Ulysses Contract, I am one of the founding members of BIIE and have a strong music and improv dance background. In future versions of the signals and systems class, I intentionally changed the theme such that I would have far less experience. In subsequent years I issued other challenges around Interactive Clothing and Toys and Games. As a further contract for myself, I have very publicly stated to others at my college that I will change the theme each year. I anticipate future topics being perhaps Disaster Relief or Military Applications.

\section{Criticism: There is Content Students Need to Know}

A criticism that is leveled against any form of inquiry based learning is that the faculty member will not cover all of the "necessary" topics. Clearly engineering students must graduate with both depth and breadth of technical skills, and the four year curriculum is a constraint. As a result, required courses must pay careful attention to accrediting bodies, professional licensing tests, industry needs, and graduate school preparation. The usual answer back is that true learning occurs when a student can transfer knowledge and skills to other situations. Inquiry based learning may not teach (from the faculty perspective) as much, but transferable learning (from the student perspective) does occur. The Faculty Ulysses Contract is a form of inquiry based learning and as such it is susceptible to the criticism above. It would be simple at this point to simply reiterate the typical answer to the critics.

The Biomedical Signals and Systems (BMEG 350) class is a core course in the curriculum and contains several ABET direct assessment points. To satisfy these requirements there are quizzes on technical material, formal team-based labs, and an individual lab practicum. The Ulysses Contract is in play only during the project. But within the project there are still some ABET direct assessment measures. I have found that with some guidance students often come up with more rigorous and creative ways to demonstrate that they have met the learning objectives. The only drawback for the instructor is developing a meta-assessement tool that can be used for all of the individual student assessments. In reality, it is easier for the faculty member because the students are doing the vast majority of the assessment themselves.

Do not mistake the above as implying that students learn whatever it is that strikes their fancy. Rather the faculty member takes a more active role in explaining the bounds of the learning. In the process, students understand in much greater depth the intentions of the faculty and better understand what it is that is being learned. Rather than learning goals and assessment being a burden, they can serve to provide clarity and help make decisions in the uncertain environment of an open-ended project. 


\section{Criticism: Learning Requires Structure}

Without a content expert, however, there is an additional and perhaps more serious concern. Can a faculty member provide the structure and feedback (both formal and informal) that are needed for learning to occur? Nearly all of learning science points to structure as a critical property of a learning environment ${ }^{19,20}$. In fact, a good portion of this paper is meant to answer this important question. Below is the seed of an answer that will be amplified throughout the remainder of the paper.

In many cases a Faculty Ulysses Contract requires more structure and feedback, it is simply of a different form. In the above biomusic example, the engineering students still learned the topics of a more traditional signals and systems course through formal homework, quizzes and labs. It was only in the semester-long project where the faculty member ceded expertise. Furthermore, there were many checkpoints, reviews (both formal and informal) and consequences for missing a checkpoint, as detailed elsewhere ${ }^{18,17}$. Students still received summative and formative feedback throughout the process. As a continuation of an answer about structure, below are the deeper theoretical and practical foundations for issuing a Ulysses Contact.

\section{Learning Theory and Real World Decisions}

There has been much learned over the past half century about how people learn ${ }^{19,20}$. One leading theory, although debated in the literature, is that of the Social Constructavists who argue that learning is a social process. Groups create knowledge for one another in a culture that is collaborative $^{21,22}$. Even when a student reads a book and 'learns on their own' this is only one small part of learning. In their reading, they have engage in the social process of reading another's words. According to the theory, part of the learning process is also demonstrating to others, in either formal or informal ways, what has been learned. The traditional classroom format is social, but it is mostly one-way from faculty to students. Inquiry-based and collaborative learning creates a two-way interaction between faculty and students as well as between students. The Faculty Ulysses Contract makes the social interaction even tighter because the faculty member is now intertwined in the social construction of knowledge. What is created is a learning community ${ }^{23,24}$ where the knowledge hierarchy becomes blurred. Students who discover something useful to the group are proud to share what they have learned, earning social capital among their peers and instructor recognition.

A more practical position is that students get better at what they practice. Like all adaptive biological entities, students will become proficient at navigating the environments they have had time to explore ${ }^{25,26}$. If their environment is highly structured, they will learn to operate in an ordered environment very well. On the other hand if the environment is entirely unstructured, they will do their best to cope with the disorder. The real world is a mix of order and disorder. So with the goal of preparing our students for the real world, it makes sense to create a classroom environment that has a balance between order and disorder.

Counter to what many faculty members might think, learning and making decisions in the real 
world (e.g. business, politics, research, and design) is achieved all the time without having a central repository of knowledge. Even decisions that appear to be made by one person are in reality socially constructed. This is the basis of the learning organization ${ }^{27}$ as well as the building of innovative cultures ${ }^{28,29}$. What a Faculty Ulysses Contract does is to allow students to make decisions in situations where the boss (in this case the faculty member) does not have all of the answers, yet can provide feedback that is both summative and formative. Someday they will likely have a boss, but that boss will not "know" the material in the same way that a faculty member "knows" the material. Perhaps the most powerful preparation a student can receive in college is how to continue to make forward process in a noisy environment when there is no ultimate arbiter ${ }^{30,31,32}$.

\section{What Students Gain}

Students stand to gain a great deal in a classroom that operates under a Faculty Ulysses Contract. Of most importance, students become their own Chief Learning Officers. Building upon business language,the faculty member may be the Chief Executive Officer (CEO), but the students are at the $\mathrm{C}$-level. And just as in the business world, a C-level employee can make very high level decisions and sometimes even challenge the CEO. For example, in business, the Chief Financial Officer (CFO) might question a CEO about a financial decision or action. A student should be in a similar position when learning is the matter to be discussed. To stretch the analogy farther, a CFO would be expected to give their opinion on financial matters but also would be required to demonstrate a high level of competence. A CFO is also more singularly focused on the financial operations of a company, just as a student should be navigating the class with a more singular focus on their own learning.

The natural extension of this thinking is to allow students to determine some of the learning objectives that supplement those chosen by the faculty member. This only makes sense in an environment where the student will at some point know more about the details of the project than the faculty member. Of course the degree of control will vary. In fact, in several of the case studies given throughout this paper, I have required students to create their own project-specific learning objects, and then self-assess their achievement of these objectives. Grades are based on the alignment between their objectives and their assessment, not whether they achieved their objective. In nearly all cases, I have found students to be harder on themselves then I would be.

Many students have not had an honest interaction with a faculty member during their time in college. To students, faculty are a stepping stone toward bigger and better things. To faculty, students are a means of propagating our hard-earned knowledge and wisdom. Both attitudes break down honest conversation. Furthermore, few students have been honestly entrusted with their own learning - faculty feel the need to micromanage most aspects of the course. A Faculty Ulysses Contract starts with the assumption that there will be an honest back and forth and that students can be trusted. This is surprising to most students. Just like Ulysses needed to trust that his men could operate on their own, we must do the same. So as not to be too idealistic, this is only a starting point - sometimes honest two-way communication and trust will breakdown. This is an important learning moment. And often a breakdown is not only easily repaired, but if handled right, can lead to better communication and trust. What emerges is a more healthy relationship. 
Students gain what they wanted all along - to learn what will help them later on. And faculty gain what they want - deeper respect from their students.

The focus so far has been largely on skills and knowledge. But as we are exiting the knowledgebased world in which we were educated, attitudes and mindsets are being recognized as more important factors of later success $33,34,35,36,37$. In the literature these attitudes include grit, curiosity, self-efficacy, the growth mindset and others. Whatever the makeup or nature of a mindset, most pedagogical methods short circuit the development of these mindsets. To take one specific mindset, we know that students are more intrinsically motivated when they have autonomy over their work, see the purpose of their work, and can gain mastery through their work ${ }^{34}$. Yet faculty are under the impression that what they cover in the classroom is the most important part of the class. By many estimates, however, only about $10-20 \%$ of a student's waking time is spent in classrooms ${ }^{19}$. So if deep learning is going to taking place, some significant learning must take place outside of the classroom. What we observe in our classrooms is therefore just the tip of the learning iceberg. Framed in this way, building intrinsic motivation in the classroom will pay off for students, not only in our classrooms but throughout their careers.

\section{Criticism: I Will Lose Control of the Class}

How does a faculty member maintain classroom order and forward progress toward learning goals? Some more concrete ideas will be presented in a later section. Here I will consider two archetypal characters that maintain control of a group. First is the drill sergeant who commands respect due to rank, and maintains order based upon the threat of punishment. We can do something similar, using our status to demand respect and grades as a weapon. The inductive approach can certainly temper the tone, but there are often some (perhaps uncommunicated) learning bar over which students are being asked to jump. Based upon this uncertainty, students may be scared or shamed into performing well.

A second approach is to become a cognitive coach. The term most often used in the learning literature is a cognitive apprenticeship ${ }^{38}$, but what is described is very much like the unique relationship between a player and coach. Whereas the coinage of our realm is the grade one receives, the coinage of athletics is playing time. Yet rather than give a one-size-fits-all approach, an athletic coach offers strategies and tactics to their players so they can try them on to see what fits best. The assessment of a player is not based soley on their performance in a game - they are assessed on process, mindset, engagement, teamwork, effort and other aspects that may not show up directly or right away. And a good coach rewards individual improvement, not performance relative to others on the team. The form of the reward (or punishment) is also varied. Unlike grades where we might bemoan inflation, playing time is a resource that is limited by the rules of the game and so coaches have found other means to reward or punish. Verbal praise, recognition by peers and other such means are sometimes more powerful. An athletic coach also recognizes that not every player will become the player they once were - in other words, not all players (in fact few) will become coaches. Perhaps most importantly, a coach is a role model. The mindset they bring to their coaching is the mindset that will spill over to their players. A good coach does not maintain order through just sticks and carrots, but rather by creating a rich learning environment where the 
rewards are multi-dimensional. Becoming a cognitive coach is an alternative that we can use in the classroom. The following case study illustrates this model.

\section{Case Study: KEEN Winter Interdisciplinary Design Experience (K-WIDE)}

Bootcamps, Hack-a-thons and other intensive experiences have become popular extra-curricular experiences at many schools ${ }^{39}$. The faculty who run these bootcamps acknowledge that they are not the experts in the particulars of the student projects. Some assign Wicked Problems ${ }^{40}$ - very large societal problem that will need to be attacked through some combination of technological, political, social and other means in a coordinated fashion. Excellent examples are the National Academy of Engineering (NAE) Grand Challenges ${ }^{41}$, Google Moonshots ${ }^{42}$ and the MIT SolveFor $\mathrm{X}^{43}$. It is known at the onset that any individual, group, or institution is not going to solve the problem in its entirety. The reason for tackling a grand challenge in a classroom or bootcamp is therefore to highlight processes, decisions and cognitive skills, as well as to build an awareness of how all significant engineering problems are embedded within larger, and often times conflicting, contexts. From a pedagogical perspective, such wicked problems become a way to prevent short circuiting of the learning process.

I have co-led a ten-day January bootcamp for second year engineers for the past four years where they tackle a Wicked Problem. They get no credit or pay and participate simply out of their own intrinsic motivation to learn something new. The details of the program and philosophy are outlined in other sources ${ }^{39,44}$, but for the purpose of this paper, what is important is that the instructors purposely pick a challenge that they know little about. This turns our role into something different - the focus is not on the products, pitches or processes but rather the mindsets that one must adopt to take on a big challenge. We asked our students to consider their project from many viewpoints - not just the 5 foot view of how to solve their problem, where most engineers spend their time, but also the 50,000 foot view of impact on the world. Near the end of the program, each student sketches out the process they followed. They were all unique, but there were some important themes. None of them were the simple design process found in textbooks. Instead, they were tangled non-linear webs of activities - exactly what is needed to solve messy tangled problems. And their drawings contained a high number of non-traditional design topics - economic, ethical, historical, social and political impact - that were integrated into the traditional design process. In essence, they had learned to view engineering design in a wider context.

Without grades or credits, our role becomes that of a cognitive coach - a motivator, guide and emotional support. All feedback becomes formative. Self-reflection naturally becomes a major focus of the program. We can praise more extremely and hold up good work as an example to the rest of the group. But, we can also take an individual aside and give them an honest, sometimes harsh, appraisal of their learning progress. There is no true penalty and we can honestly give feedback without a student fearing the impact on their grade.

The first offering of the program focused on the NAE Grand Challenge Urban Infrastructure. At the end of the ten days, we had six new products. One was a bus seat that would be a regular seat most of the time, but fold up into the ceiling, and would have straps to accommodate more people 
during rush hour. Another was a playground swing that would harvest energy and create a wireless network for the parents, or in the developing could store that energy to be used to light houses at night. Other themes have been Human Weight and Disaster Relief.

\section{Why Engineers?}

A Faculty Ulysses Contract could very likely be useful in other disciplines. But it is particularly important for engineering students at this time. The history of engineering has been one of oscillations between a focus on theory and practice ${ }^{45}$. We are in the midst of engineering becoming more about practice in the real world. The consequence is that more and more engineers are in direct contact with many arenas where there is no "right" answer and a solution must be socially constructed. This is an important lesson for any young engineer, as their role will be to create solutions in the context of a complex problem. It is not that raw knowledge is unimportant or should not appear in an engineering curriculum, but rather that at some point the "right" answer must include the context of the problem that is being solved.

An appreciation for context is important, but all too often it is forced in an engineering curriculum - we teach topics such as ethics and economics in particular courses and do our best to make them relevant. A Faculty Ulysses Contract naturally brings in many contexts. The open-ended nature of the problems are very rich with opportunities to point out where economics, ethics, politics, standards, marketing, and a whole host of other areas become important. For example, in the biomusic project a group of students were attempting to understand how keystrokes on their laptop were being mapped to ASCII characters in software. This provided an excellent opportunity for the entire class (including me) to download the standard (ISO/IEC 9995) and take a look at it. We followed this up with a short, general discussion of standards. Although standards are embedded within another class in our curriculum, many students commented that this was the first time that they understand why the faculty made such a big deal about standards.

\section{What Faculty Gain}

There are significant benefits to the faculty member too. One of the important functions of a faculty member is to be a role model ${ }^{38}$. In the long-run, we take much greater pride in the example we have set for students rather than the knowledge our students have gained from us. It is what they remember after they graduate. Yet in most teaching situations we are an idealized role model - measured by how "smart" someone can become after years of study. We keep our cool and make rational decisions because we already know where the class is going. The Faculty Ulysses Contract can establish a faculty member as a much more realistic role model. We can display for them good habits of mind and action when they matter the most - when conditions are uncertain ${ }^{30,31}$.

Courses that use a Ulysses Contract reward students who adopt a learning mindset. In the absence of a "right answer" to grade, the grading must instead focus on good processes, reasonable decisions, and best intentions. The result is that faculty can quickly identify those students who 
may not perform the best in a traditional class, but are self-motivated, can make good decisions in a fuzzy environment, and don't get as frustrated by set-backs. I have found that these are the types of students who will succeed in the more open-ended environment of my research lab.

One rationale for the teacher-scholar model ${ }^{46}$ at many institutions is that the two primary jobs of a faculty member should work synergistically. A Faculty Ulysses Contract can be a mechanism for a faculty member to remain current in a field. This is of particular importance when a faculty member teaches some classes that are not squarely within their narrow research program. On the teaching side, there are rewards too. Simply dusting off notes and assigning the same (or very similar) projects from year to year is not a sustainable model for a career. Faculty will discover new pedagogical tools because they will actively search out other instructors and tools that will aid them. In this regard they will become more capable of guiding future students, both in the classroom and the research lab.

The Ulysses Contract also can have a more profound impact on the mindset of the faculty member. All of our training is based on the idea that content comes first, and it is through content mindsets will emerge. This is the basis of most education all the way through graduate studies. What the Faculty Ulysses Contract highlights is that when mindsets come first, knowledge in a new content area can more easily follow. For faculty, this realization can encourage more adventurous exploration in their own projects.

\section{The Institute for Leadership in Technology and Management (ILTM)}

Traditional case studies lead a reader through a dilemma where a decision must be made in an uncertain environment. The way most case studies are taught is to read the setup of the problem first, let students struggle with the problem, and think about what their actions might be. Then the real decisions and actions are revealed and the consequences analyzed. A Live Case Study ${ }^{47}$ is a bit different because the decision has not yet been made by the company - it is a "live" problem.

Live case studies form the basis for the Institute for Leadership in Technology and Management $(\text { ILTM })^{48,49}$. ILTM is a six-week, non-credit bearing summer program where an interdisciplinary group of students engages in a live consulting project for an industry sponsor. During the day students visit corporate sites, engage with C-level and VP-level executives, and hear academic talks from faculty on topics that range from marketing and ethics to engineering design. During non-class times, students are engaged in their consulting projects. They visit their client, conduct regular email, phone and Skype conversations and conduct a great deal of outside research. Through their research they must refine the problem statement, generate possible solutions, make recommendations and then give guidance as to how to execute those recommendations. The program culminates in a 100+ page consulting report and a three hour consulting debrief with the clients. Students do much more than simply make recommendations; they share the academic frameworks that underly their recommendations. Throughout this experience, the faculty mentors can only act as guides.

Over the 20+ years of the history of the program, many businesses have gone on to not only 
implement the solutions, but also hire students after they graduate. In a study that is ongoing, the clients report out that the main reason they hire ILTM alumni is because they know that they make critical decisions in an open-ended environment.

\section{What Students and Faculty Gain}

There are some elements of a Faculty Ulysses Contract that help both students and faculty. At some very basic level, learning requires change. That change might be contained within one person or within many, but the total learning that takes place will almost by definition be higher when a Faculty Ulysses Contact is issued. If the goal of a classroom is to maximize learning, then a co-learning model certainly is rich with possibilities. It is often the case that students learn a concept, procedure or process that the faculty do not know themselves. It is important for the faculty member to notice this, not be threatened by it, and have mechanisms by which the students can share their experience. Accomplishing this flips the model of who is the content expert.

Stories are created in classes with Faculty Ulysses Contracts. It is important for students to recognize the stories they are creating. I will often pair projects with a sequence of reflective assignment to bring out these stories. The resulting stories become powerful examples that can be used during interviews to demonstrate how one will function in a situation that more closely mimics the real world. The projects can also become outstanding show pieces for a faculty member too, often leading to recognition as an innovator.

\section{Criticism: I Already Do This}

Many instructors have already adopted some form of Faculty Ulysses Contracts with their students, for example in the arena of design, research and advising student clubs. Recognizing a contract for what it is means that you can become more intentional about building a robust learning environment. It can also help prevent falling into the trap of reverting to the classroom persona of the content expert.

Research projects engage students in an area where the faculty member is an expert, but does not have all of the answers. We know from our training that research is inherently an adaptive process. The learning value of taking on a research student is therefore to show them up close how to navigate a path by being an adaptive expert. The key difference, however, is that in most research experiences, the faculty member still maintains the role of expert and arbiter. What is critical to student's learning in these situations is how much control they have over the decisions they are making. A faculty member can be on a spectrum from making all decisions without explaining them, to allowing the student to be self-directed in their decision making. This spectrum mirrors the typical research maturity from undergraduate, to graduate, to post-doctoral fellow to faculty member. A Faculty Ulysses Contract can help transition students in our research labs along this spectrum from not making any decisions to making most of their own decisions. 
Many senior design programs operate with a type of Faculty Ulysses Contract - either by working with an external partner or on internal projects that have not been solved (e.g. a Live Case Study). The faculty are often not exactly within their area of expertise and are learning alongside their students. Perhaps this is one of the reasons why some departments have certain faculty who gravitate toward senior design, while others do everything to avoid design courses. Likewise, among those design oriented faculty, some gravitate toward legacy projects, where they already have a much better feel for the project, while others may move toward new projects. The measure used for research can be applied here as well - how much decision making power do students have over the path that is followed? It is likely that the more decision making power they have, the more they will learn.

Advising student clubs is another arena where a faculty may not have content expertise but can share processes and mindsets. A great deal of learning can occur when students take on a leadership role in a student-run club. This is a parallel concept to them becoming Chief Learning Officers. Learning how to guide, rather than drive, a student club can be a powerful way to experiment with a Faculty Ulysses Contract.

\section{Case Study: Quantitative Neurophysiology Project (BMEG 441)}

Cooperative and Collaborative Learning ${ }^{24,23,22,21}$ occurs when groups learn from one another. In many classes the cooperative dynamic that arises is orchestrated in some way. For example, the faculty member may break students into groups to accomplish some task. In a Faculty Ulysses Contract, cooperation can arise more naturally. As long as I do not forbid or discourage it, I have found that students naturally share hard earned information with their peers. For example, I have watched, on multiple occasions, as one person in a group would take charge of the software (or hardware) for their project, and then schedule meetings (unbeknownst to me until later) with the other software (or hardware) gurus from other groups. I become a near-peer and am engaged in the learning community too.

For nearly a decade I have taught a senior-level neural engineering elective course ${ }^{50,18}$. In addition to the theoretical content, an individual project provides the opportunity for students to chose a particular neural-related topic that is not covered in the course. Around this topic they much construct three artifacts for three different audiences. For the Layperson, artifacts can range from a pamphlet to a commercial to a science fiction story. For the Engineer, artifacts can range from an annotated drawing to a computer simulation. For the Clinician/Scientist the artifact could be the introduction and methods for an experiment, a review article or in some cases an experiment they conducted. Along the way students must collect and analyze examples of the types of artifacts they will create, and extract the features that will make them successful at conveying information to their target audience. As I am not an expert in their areas, students are required to have a "Buddy" - a peer from class that they meet with on a regular basis to share ideas, test communication modes and critique their analysis of the found artifacts. While I oversee this process, a significant portion of the assignment (both in terms of work and evaluation) is to learn from and with a peer. Over the years, the range of projects and combination of technical depth and creativity has been far beyond what I have seen in my more traditionally taught courses. 


\section{Assessment}

The student feedback has been obtained from all of the case studies above. Preliminary assessment has taken two forms. First are comments that appear on university-mandated course evaluation forms ( $\mathrm{n}=177$ across multiple classes and course offerings). Second is a more targeted survey to the Fall 2014 Neural Signals and System class $(n=14)$ and Biomedical Signals and Systems $(n=18)$ class. Both data collection methods have been approved by the Bucknell Institutional Review Board.

\section{Course Evaluations}

At the conclusion of all courses (e.g BMEG 350 and BMEG 441) students provide both numerical and open-ended feedback. In general the open ended feedback is on the general strengths and weaknesses of the course. During K-WIDE and ILTM, students are asked throughout the program to reflect on various aspects of their experience. Questions have not been targeted specifically to the Faculty Ulysses Contract concept. The comments below have been chosen due to their relevance to the current project.

Many students expressed frustration with the process. Most students made some reference to the environment being one that encouraged self-directed growth. And the freedom they had in making decisions and their importance of those decisions to others. Some students made the connection to the real-world. And they commented on how the process necessarily needed to be adaptive. In all of the team-based projects, students had insights into group work. Student comments to support these finds are in Appendix A.

\section{Faculty Ulysses Contract Survey}

To gain more targeted insights, the following questions were asked of the Fall 2014 Neural Signals and System class and Biomedical Signals and Systems classes as part of their end-of-course evaluations.

1. What aspects of the project structure/assignments helped the most?

2. What was the most difficult/frustrating part of the project?

3. In what ways did you find yourself coping with the instructor's lack of knowledge about the specifics of your project?

4. What was most rewarding aspect of this approach?

5. Did it help or hurt that the project was team-based?

6. What suggestions do you have for the future?

Many students reiterated similar comments to those above. I focus below on the themes that arose from their comments. Many students enjoyed the freedom they had in choosing their project and 
its direction. Students found a range of strategies for dealing with the lack of instructor content knowledge. Some students recognized and could express the connection between the Faculty Ulysses Contract and their growth. And some students provided useful opinions on the the process. There were certainly some minority of students who were critical of the approach. Student comments to support these finds are in Appendix B.

Evaluation is ongoing and future publications will refine the questions as well as gather data from ILTM and K-WIDE.

\section{Tools for Success}

Trying a Faculty Ulysses Contract can be daunting and is perhaps not for all faculty. Offered below are some general thoughts on trying a Faculty Ulysses Contract.

- If you are the expert, then feigning ignorance is not a Faculty Ulysses Contract and is instead a pedagogical technique - "I know but I want you to discover it for yourself". This is more akin to the inductive or problem based learning approach.

- The idea of a Faculty Ulysses Contract can be tried out by being more intentional with research students, senior design advising and student clubs.

- I presented the Faculty Ulysses Contact as an all-in process, where an entire course or project is modified. In reality this is far from necessary. It is possible to set aside just one class to try with your students.

- The mindset that a faculty member must have to issue themselves a Faculty Ulysses Contract spills over to the students.

- If you want students to learn basic knowledge or skills, a contract may not be the best option. However, if the intent of the course is: 1) to go more deeply into some set of knowledge or skills, 2) to target higher level cognitive skills (e.g. upper levels of Bloom's Taxonomy) or 3) to target a mindset, a Faculty Ulysses Contract may be a useful tool.

- Students will be uncomfortable. Recognizing that will be a key to success. Reassuring them that you know this is hard for them, and being honest that this is actually harder for you as well, will help build some empathy. Praise when they get something right is critical as is encouragement to adopt good methods and processes rather than to get the answer.

- Reward mindsets, effort, processes and progress rather than outcomes. Learning objectives are so often skill- and knowledge-based because these can be easily measured. But deep down, most higher level objectives are not content specific. It is possible to reward decisions and intentions rather than answers.

- Reflection is a powerful tool in highlighting learning in many environments ${ }^{3,22,38}$. But reflection becomes vital in open environments. A Faculty Ulysses Contract is not just all about doing - reflection is necessary for deep learning to occur. 
- Reviews (both formal and informal) are a type of group reflective exercise. During a project, it is possible to arrange for various panels composed of students, other faculty, or outside constituents to give constructive feedback. After a project is over it can be useful to have a post-mortem. Another variation is to have a pre-mortum at the beginning of a project with the goal of identifying possible process bottlenecks and discuss previous experience that might be brought to bear in navigating the project.

- Like any pedagogical approach, one becomes better and more confident with practice.

There are also some more specific tricks that I have found helpful

- Students should be given the opportunity to show work that will demonstrate how they have become experts in something. This may occur at any point in the course, but it should be structured in such a way that students can share with others how far they have come.

- Let students know what you are doing and why? Dedicate some classroom time to talk about the pedagogical reasons for issuing a Faculty Ulysses Contract and express that you are excited to try this out yourself. Let them know that you are trusting them. This may include that you want them to become their own chief learning officers and that you view your role as a cognitive coach.

- Students will need to be reminded at times that you are still in charge and have many things to teach them. Wait for moments when you can show students your expertise. For example, there are wonderful moments when I have been able to step in and troubleshoot a circuit in one minute (it is almost always a problem with a ground!) that a student has spent hours trying to fix. This type of moment is more powerful than anything I could say.

- Peer input and collaboration across groups can arise naturally. This should be encouraged whenever it is observed.

- It can help to have ungraded or lightly graded assignments that lead to a larger graded work. This allows faculty to give guidance and feedback without it being punitive. The environment in the class can absorb risk and refocuses students on learning lessons early so they can be used later in the course. It also sends the message that you want them to do well.

- Just like in diving or gymnastics, where some routines have a higher possible point total, project grades can have a maximum point total. I have used only a few levels $-100 \%, 90 \%$ and $75 \%$. When students turn in initial project proposals, I score them by how ambitious they are. Groups then can make the decision to scale up or down their project. In this way it is clear that there are two ways of arriving at a grade of $87 \%$. It could be that a $90 \%$ project was attempted and done well, or it could be that an ambitious project (100\%) was attempted but fell somewhat short. This scoring systems keep students honest about the very real balance between ambition and execution.

- It is sometimes possible to have flexible deadlines for assignments. This is important especially when the pathway to be followed is unknown. The group is responsible for turning in the assignment sometime within a range of times. Left to their own devices, I have found that students will always turn in assignments at the last possible date. To mitigate this, I will often have a target date within the range. If a group does not turn in their assignment by that 
target date, that immediately triggers a meeting with me to determine why they are behind.

- I have sometimes drafted up a written contract with my students to make clear how much freedom they have been granted. The contract can scale the degree of decision making freedom. I often will scale the freedom to the level of the course - less freedom in lower level required courses, more freedom in upper level non-credit baring programs.

\section{Case Study: A War Story}

This article has painted an admittedly idealistic picture of implementing a Faculty Ulysses Contract. There will be tension between the faculty, who stress learning, and students, who may myopically focus on grades. This problem is exacerbated when the faculty member gives up control of the content. Many of the academically successful students will rebel against a methodology that rewards learning in a way that they have not encountered before. It is not easy to be a cognitive coach to everyone, and in larger classroom it may not be possible. All of these issues and more arose in one implementation of the signals and systems course.

My teaching evaluations for my Fall 2013 offering of BMEG 350 were almost a full two points (on a five point scale) below my usual averages. In written comments the students complained that I did not know the specifics of their project. Others went as far as to state that I should not be teaching this particular course because I had not mastered the material (I have written textbook on signals and systems). Some said that I was unfair because some groups received more help than others (the first time I have been accused of being unfair). Still others said that this course had nothing to do with engineering, asking for problem sets with definite solutions. Perhaps the most damning, however, was their claim that they didn't learn anything. This was demonstrably false in that their projects were some of the best I had seen.

What was interesting was what happened after the course was over. Students went off to other classes, and later that summer to internships. They are currently halfway through their senior design project. And what has come back from multiple students are updated comments. For example, one student related that in retrospect the experience marked when he began to think of himself as an engineer. Another student said that she finds herself talking about the project as her most significant accomplishment so far. Two others have said that the project is their go-to example when talking to family members, friends and potential employers. The most recalcitrant student in fact became my teaching assistant for the following year. He did a wonderful job, not only in helping students, but in making the case for a Faculty Ulysses Contract to this new group of students.

\section{Conclusion}

Faculty have worked hard to be the experts in their discipline. Ceding the position of expert is not only terrifying but seems to run against our own investment in learning an area in great depth. But just as Ulysses gave up his authority to ensure a better future for all those aboard his ship, we can do the same within our classrooms. The Faculty Ulysses Contract introduced here is not 
as much a pedagogical technique as it is a mindset that a faculty member adopts. We become cognitive coaches and our students become their own chief learning officers. The end goal is to guide students in the development of good learning habits, the confidence to make their own decisions, and the ability to find or create their own content knowledge. All of these qualities are more important than raw content, especially given that jobs are shifting away from the algorithmic manipulation of content. We must remember that we are training students for jobs that do not yet exist. To remain functioning members of the workforce for a 40+ year career, they will need to continue to develop these skills and our classes can be a first important step.

\section{Acknowledgement}

The authors gratefully acknowledge the Design Education Lab at Stanford University, as well as members of the Biomedical Engineering Department and Teaching and Learning Center at Bucknell University

\section{References}

[1] URL http://www. gutenberg.org/ebooks/1727.

[2] Michael J. Prince and Richard M. Felder. The many faces of inductive teaching and learning. Journal of College Science Teaching, 36(5), 2007.

[3] Kolb. Experiential learning: Experience as the source of learning and development. Vol. 1. Prentice Hall, 1984.

[4] Paul R Sackett, Neal Schmitt, Jill E Ellingson, and Melissa B Kabin. High-stakes testing in employment, credentialing, and higher education: Prospects in a post-affirmative-action world. American Psychologist, 56(4): $302,2001$.

[5] Borrego, Maura, Froyd, and Hall. Diffusion of engineering education innovations: A survey of awareness and adoption rates in us engineering departments. Journal of Engineering Education, 99(3):185-207, 2010.

[6] Richard M. Felder, Rebecca Brent, and Michael J. Prince. Engineering instructional development: Programs, best practices, and recommendations. Journal of Engineering Education, 100(1):89-122, 2011. ISSN 2168-9830. doi: 10.1002/j.2168-9830.2011.tb00005.x. URL http://dx.doi.org/10.1002/j.2168-9830.2011.tb00005.x.

[7] John Dewey. Experience and education. Simon and Schuster, 2007.

[8] Rebecca Dresser. Bound to treatment: the ulysses contract. Hastings Center Report, 14(3):13-16, 1984.

[9] Ryan Spellecy. Reviving ulysses contracts. Kennedy Institute of Ethics Journal, 13(4):373-392, 2003.

[10] Joseph A Rogers and J Benedict Centifanti. Beyond" self-paternalism": Response to rosenson and kasten. 1991.

[11] Christine Jolls. Contracts as bilateral commitments: A new perspective on contract modification. The Journal of Legal Studies, 26(1):203-237, 1997.

[12] Shaun Hargreaves-Heap and Yanis Varoufakis. Game theory: a critical introduction. Routledge, 2004. 
[13] Charles Duhigg. The power of habit: why we do what we do in life and business. Random House LLC, 2012.

[14] Kenji Matsumoto and Keiji Tanaka. The role of the medial prefrontal cortex in achieving goals. Current opinion in neurobiology, 14(2):178-185, 2004.

[15] Michael J Prince and Richard M Felder. Inductive teaching and learning methods: Definitions, comparisons, and research bases. Journal of engineering education, 95(2):123-138, 2006.

[16] Fernando Mortera-Gutiérrez. Faculty best practices using blended learning in e-learning and face-to-face instruction. International Journal on E-learning, 5(3):313-337, 2006.

[17] Joseph Tranquillo and Daniel Cavanagh. A project-driven approach to biomedical signals and systems. 2007.

[18] Joseph Tranquillo. The t-shaped engineer: Connecting the stem to the top. 2014.

[19] Andrew N Meltzoff, Patricia K Kuhl, Javier Movellan, and Terrence J Sejnowski. Foundations for a new science of learning. science, 325(5938):284-288, 2009.

[20] John D Bransford, Ann L Brown, and Rodney R Cocking. How people learn: Brain, mind, experience, and school. National Academy Press, 1999.

[21] A Sullivan Palincsar. 12 social constructivist perspectives on teaching and learning. An introduction to Vygotsky, page $285,2005$.

[22] Beaumie Kim. Social constructivism. Emerging perspectives on learning, teaching, and technology, pages 1-8, 2001.

[23] Etienne Wenger. Communities of practice: Learning as a social system. Systems thinker, 9(5):2-3, 1998.

[24] Kenneth A Bruffee. Collaborative learning: Higher education, interdependence, and the authority of knowledge. ERIC, 1999.

[25] Dante R Chialvo. Psychophysics: Are our senses critical? Nature physics, 2(5):301-302, 2006.

[26] Dante R Chialvo. Critical brain networks. Physica A: Statistical Mechanics and its Applications, 340(4):756$765,2004$.

[27] Peter M Senge and Joel Suzuki. The fifth discipline: The art and practice of the learning organization. Currency Doubleday New York, 1994.

[28] Thomas Kelley and Jonathan Littman. The ten faces of innovation: IDEO's strategies for defeating the devil's advocate and driving creativity throughout your organization. Random House Digital, 2006.

[29] Jeffrey H Dyer, Hal B Gregersen, and Clayton M Christensen. The innovator's dna. Harvard Business Review, 87(12):60-67, 2009.

[30] Nate Silver. The signal and the noise: Why so many predictions fail-but some don't. Penguin, 2012.

[31] Daniel Kahneman. Thinking, fast and slow. Macmillan, 2011.

[32] Shona L Brown and Kathleen M Eisenhardt. Competing on the edge: Strategy as structured chaos. Harvard Business Press, 1998.

[33] Carol Dweck. Mindset: The New Psychology of Success. Ballatine Books, 2007.

[34] Daniel Pink. Drive: the surprising truth about what motivates us. Riverhead Books, 2009.

[35] Bandura. Self-efficacy: Toward a unifying theory of behavior change. Psychological Review, 84, 191-215., 84: $191-215,1977$.

[36] Paul Tough. How children succeed. Random House, 2013.

[37] Ian Leslie. Curiosity: The desire to know and why your future depends on it. Basic Books, 2014. 
[38] John Seely Brown, Allan Collins, and Paul Duguid. Situated cognition and the culture of learning. Educational researcher, 18(1):32-42, 1989.

[39] Charles Kim and Joseph Tranquillo. K-wide: Synthesizing the entrepreneurial mindset and engineering design. 2014.

[40] Valerie A Brown, John Alfred Harris, and Jacqueline Y Russell. Tackling wicked problems through the transdisciplinary imagination. Earthscan, 2010.

[41] URL http://www.engineeringchallenges.org/.

[42] URL http://www.businessweek.com/articles/2013-05-22/inside-googles-secret-lab.

[43] URL https://www. solveforx.com/.

[44] URL http://www.bucknell.edu/kwide.

[45] Henry Petroski, Henry Petroski, and Henry Petroski. To engineer is human: The role of failure in successful design. Vintage books New York, 1992.

[46] Ernest L Boyer. Scholarship reconsidered: Priorities of the professoriate. 2014.

[47] Elizabeth LR Elam and Harlan E Spotts. Achieving marketing curriculum integration: A live case study approach. Journal of Marketing Education, 26(1):50-65, 2004.

[48] Keith W Buffinton, Kathryn W Jablokow, and Kathleen A Martin. Project team dynamics and cognitive style. ENGINEERING MANAGEMENT JOURNAL-ROLLA-, 14(3):25-34, 2002.

[49] URL http://www.bucknell.edu/iltm.

[50] Joseph Tranquillo and Daniel Cavanagh. Building engineering communication skills through short assignments. 2007. 


\section{APPENDIX A - Student Course Assessment}

Many students expressed frustration with the process

- "Although I did learn a lot about signals and systems, in the end I was frustrated almost the entire course". (BMEG 350)

- "We tried a project that was way too hard. We should have backed off once we realized we wouldn't make it". (BMEG 350)

- "After the first day or two I could see glimpses of "maybe this is could be good for me..." but the anguish I was going through really made me question why I had paid to shortened my break and do this but now I don't and don't expect to regret anything. In just a few days I have not only made huge gains in my technical and electrical understanding, but I'm seeing the physical products of all the planning we struggled through before and it's making it far beyond worth it." (BMEG 350)

- "I was very frustrated throughout the whole assignment, but I learned to cope with inner anger and still be productive". (ILTM)

- "The mistakes and successes that my group experienced along the way will also be important lessons that I will consider in my future endeavors". (ILTM)

- "Sometimes I felt direction-less, sometimes even helpless. But it is such unfamiliar content and process that pushed me out of my comfort zone. I learned more from working on my project than I ever expected!" (ILTM)

- "All the members of my team were put in a very uncomfortable situation and we were all faced with an ethical dilemma that we were not suited to deal with". (ILTM)

- "More structure for the project would help but would ruin our ability to pick our own path." (BMEG 441)

Most students made some reference to the environment being one that encouraged self-directed growth

- "This course changed me as a person." (BMEG 441)

- "It really allows individuals to learn and grow in an environment free of restriction and order, which is great in order to express that creative element within". (BMEG 350)

- "It allowed for personal discover that help solid many of the key learning objectives of the class". (BMEG 350)

- "I challenged myself to learn something new, but rather the entire process has challenged me to constantly learn and adapt”. (K-WIDE)

- “... we were inspired and motivated enough to overcome our lack of knowledge". (K-WIDE)

- "I think the most valuable things I have learned so far is how to go after and achieve my own goals and how to teach myself". (K-WIDE)

- "This experience so far has definitely made me more confident in my engineering abilities". (K-WIDE)

- "This program pushed me beyond capacity and really taught me what I am capable of doing". (ILTM)

- "The playing field was leveled in terms of who was a good engineer and who was not. And I found out that I'm a pretty good engineer". (BMEG 350)

- "Being thrown into a difficult project and succeeding has definitely improved my confidence. I really proved to myself what I am capable of and will refuse to do anything less”. (ILTM)

- " I learned so much more because I got to learn about things that fueled my interests." (BMEG 441)

- “ I had never had such free reign on a course and I really enjoyed seeing how diverse everyone's projects became." (BMEG 441) 
- “....requires you to think very very deeply about the topics. I was surprised how much I liked that". (BMEG $350)$

And the freedom they had in making decisions and their importance of those decisions to others

- "they are not looking over our shoulders the whole time, helping us deal with all the little hiccups we have had. We really have to figure out everything on our own". (K-WIDE)

- "Its hard to explain but the freedom to be able to go out and create your own vision, your own project and be solely responsible for its completion is a unique experience that I am taking much from". (K-WIDE)

- "It was up to the individuals within the team to hold each other accountable and work on their own schedules to meet the requirements". (K-WIDE)

- "I have also learned more about how my decisions and actions can affect more people than I may realize". (ILTM)

- "He trusted our group to do a good job at the project." (ILTM)

- "I found it really interesting to start from scratch. It helped to teach us how to use outside resources as there were many obstacles that we had to overcome when designing the project". (BMEG 350)

Some students made the connection to the real-world

- "The project felt more like an assignment in the real world, rather than a 'stupid' college project". (BMEG $350)$

- "The project seemed to diverge further and further from the textbook as we worked more on the project". (BMEG 350)

- "the real world is never as straightforward as we plan it to be".(K-WIDE)

- "That experience of problem solving and diagnosing is not something that can be learned from a textbook and is a truly valuable asset I could bring to a company." (BMEG 350)

- "A much greater understanding of the professional process and what types of projects you have to do in the "real world". I now feel much more comfortable "tossing around" business ideas and concepts; I gained a lot from viewing the business world from all different perspectives." (ILTM)

- "It presents a real life situation in which it's ambiguous and realistic. We learned how to deal with these circumstances and get results." (ILTM)

- "KWIDE prepares me for the working place, helps me recognize the potential that I have by trying out new things and taking risks knowing that I might fail but would learn in the end". (K-WIDE)

And they commented on how the process necessarily needed to be adaptive

- "As much as we tried to think ahead to plan every step that we would need to create, every day we faced new challenges that we did not previously foresee and we had to design a new plan to work around them". (K-WIDE)

- "It took me a while to understand that even the most difficult moments are essential to the design process and creating a meaningful and impactful product". (K-WIDE)

- "Our instructors actually wanted us to fail, and learn and then fail again". (K-WIDE)

- "Books are good, but they just can't give you the lessons you learn from actually working on a project. I also learned that the engineering design process isn't a perfect by the book system. It constantly changes and adapts to what you are working on and is much more work than I ever imagined". (K-WIDE) 
- "As Bucknell Engineering students we're uncomfortable with failure. I learned that real engineers, innovators, and even professors can and will fail". (K-WIDE)

In all of the team-based projects, students had insights into group work

- "It gave us an opportunity to work on making group decisions, troubleshooting making something work - this was the first project I've worked on where results were a real portion of the grade - not as process dependent as previous projects". (K-WIDE)

- "I disregarded my doubts of others and put my full faith in my team as we each took over separate aspects of the project. Completion of the project would have been impossible if we hadn't been able to fully invest ourselves in our respective duties. To do that, we needed to learn to trust each other." (BMEG 350)

- "It was clear that when someone was passionate about the work they were doing they produced much better quality". (ILTM)

- "I learned how to deal with different personalities and how to leverage different peoples skills in different scenarios". (ILTM)

\section{APPENDIX B - Student Survey Comments}

Many students enjoyed the freedom they had in choosing their project and its direction

- "There were nearly infinite possibilities of what we could do. It was fun to be both technical and creative at the same time".

- "I thought the lack of your (faculty) knowledge helped created an incredible range of projects that all truly excelled in many areas".

- "I had little outside influence from you and was able to really create something and tailor my project to my own interests".

- "When you are your project's own 'boss' and nobody else knows how to solve your problems, there are times when you are just hopeless - but you find a way to find the answers".

- "Making my own decisions was the best part".

- "I don't know if I ever produced something that was so much $100 \%$ my own. There was never a need to compromise."

- "The end product was completely, wholly and fundamentally mine. And I was impressed with my final documents and how much I actually learned".

Students found a range of strategies for dealing with the lack of instructor content knowledge

- "I found myself talking to my peers a lot more and using them as resources".

- "Buddy meetings were helpful. I think I will find buddies in the future".

Some students recognized and could express the connection between the Faculty Ulysses Contract and their growth

- "All the engineering, all the thinking, all the philosophy, all the work was done by me. The result was quite surprising".

- "I learned more in this class about my own potential than any other class I have ever taken".

- "I am really proud of the work I completed". 
- "I learned to actually enjoy ambiguity because of the freedom it provides".

- "It gave me this confidence to believe that I am capable of learning other stuff from scratch, and after a little guidance, all by myself".

- "Our team learned how to really scope a project and not pick something that was too big or too small for us and our skills, not what the instructor thought was the right size".

- "We were able to push ourselves, and wanted to, but to stay within our own personal limits. I think everyone was stretched".

- "We truly understood what we were doing and why."

And some students provided useful opinions on the the process

- "It was awesome to work with my professor to troubleshoot rather than him simply telling me how to fix the problem".

- "I found out that the enthusiasm of the instructor with your projects is more important than his knowledge about it".

- "I wasn't constantly worried about if I knew the material well enough. It allowed me to freely explore in my own direction knowing that the instructor wasn't able to judge my project based on the content but rather the decisions I was making. I also felt like ti [sic] made the project more enjoyable for him too."

- "The assignments and the timeline allowed our team to assess the feasibility of what we wanted to accomplish for our project, but the decisions were still up to us."

- "Adding a midterm grade would be really helpful".

- "Capping groups at 4 would be good. 5 was too many".

There were certainly some minority of students who were critical of the approach

- "I did not like this method and I think I would have learned a lot more if he actually knew what he was talking about".

- "The most difficult part was receiving no graded feedback throughout the project from the instructor". 